\title{
New strategies for neuroprotection in glaucoma, a disease that affects the central nervous system
}

\author{
Carlo Nucci $^{\mathrm{a}, *}$, Rossella Russo ${ }^{\mathrm{b}, \mathrm{c}}$, Alessio Martucci ${ }^{\mathrm{a}}$, Clarissa Giannini ${ }^{\mathrm{a}}$, Francesco Garaci ${ }^{\mathrm{d}, \mathrm{e}}$, \\ Roberto Floris $^{\mathrm{d}}$, Giacinto Bagetta ${ }^{\mathrm{b}, \mathrm{c}}$, Luigi Antonio Morrone ${ }^{\mathrm{b}, \mathrm{c}}$ \\ a Ophthalmology Unit, Department of Experimental Medicine and Surgery, University of Rome Tor Vergata, Rome Italy \\ ${ }^{\mathrm{b}}$ Department of Pharmacy, Nutritional and Health Sciences University of Calabria, Arcavacata di Rende, Italy \\ ${ }^{\mathrm{c}}$ University Center for Adaptive Disorders and Head Pain, Section of Neuropharmacology of Normal and Pathological Neuronal Plasticity, \\ University of Calabria, Arcavacata di Rende, Italy \\ ${ }^{\mathrm{d}}$ UOC Neuroradiologia, Department of Biomedicine and Prevention, University of Rome Tor Vergata, Italy \\ e San Raffaele Cassino (FR), Italy
}

\section{A R T I C L E I N F O}

Article history:

Received 29 December 2015

Received in revised form

23 March 2016

Accepted 14 April 2016

Available online 16 April 2016

Keywords:

Glaucoma

Neuroprotection

Retinal ganglion cell

Optic nerve

Intraocular pressure

\begin{abstract}
A B S T R A C T
Glaucoma is a disease where retinal ganglion cells (RGC) are specifically affected though a number of evidences endorse the hypothesis that glaucoma is a neuro-degenerative disorder of the central nervous system and suggest a possible connection between glaucomatous damage and cerebrovascular alterations. The mechanisms underlying RGC loss are not yet fully known but alterations of the autophagy machinery have been recently proposed as a potential contributing factor as for Alzheimer's disease. Here we review the current literature on new strategies for neuroprotection in glaucoma, focusing on pharmacologic strategies to minimize RGC damage.
\end{abstract}

(c) 2016 Elsevier B.V. All rights reserved.

\section{Introduction}

Glaucoma is currently recognized to be a multifactorial, progressive, neurodegenerative disorder characterized by the death of retinal ganglion cells (RGCs) associated to the loss of axons that make up the optic nerve. These ultrastructural alterations progressively evolve and clinically manifest with increased excavation of the optic disc and consequent specific and irreversible visual field (VF) defects resulting in visual disability and altered quality of life (Cesareo et al., 2015a). With more than 60 million people affected, glaucoma is actually recognized the leading cause of irreversible blindness worldwide (see Cedrone et al., 2008, 2012; Nucci et al., 2005a).

Several clinical studies demonstrated that increased intraocular pressure (IOP), over the levels considered physiological, is the main risk factor for the onset and progression of neuronal damage. In particular, the Collaborative Normal-Tension Glaucoma Study (CNTGS) endorsed the hypothesis that IOP reduction could prevent visual field deterioration. (Group CN-TGS, 1998a, 1998b) Concordantly, the Ocular Hypertensive Treatment Study (Kass et al., 2002) and the Early Manifest Glaucoma Trial (Heijl et al., 2002),

\footnotetext{
* Corresponding author.

E-mail address: nucci@med.uniroma2.it (C. Nucci).
}

respectively, showed that reducing the IOP by using ocular medications is effective in preventing the onset or delaying the progression of the disease. In accordance to these data, glaucoma therapy is currently based on IOP reduction by medical, surgical or parasurgical treatments. However, there is a percentage of patients that experience disease progression, despite their IOP values do not differ from the normal range or are satisfactorily controlled by therapy (Leske et al., 2003). In this regard, it has been suggested that RGCs death is not related to an absolute IOP value but is linked to individual susceptibility (Osborne et al., 2006).

Therefore, despite the IOP represents a risk factor widely documented, glaucoma researcher are trying to develop IOP independent treatments for the disease based on neuroprotection (Regine et al., 2006; Kersey et al., 2013). The need of neuroprotective treatments for glaucoma is also supported by two recently investigated aspect of glaucoma disease: the involvement of the central area of the visual system and the links with neurodegenerative diseases of the central nervous system.

\section{Brain involvement in glaucoma: MRI studies}

Glaucoma is a progressive disease characterized by apoptosis of the RGCs, which are considered an extension of the central 
nervous system (CNS). It is now believed that neuronal degeneration in glaucoma is not limited to the eye but also extends, triggered by different molecular pathways, to the central visual areas, affecting the lateral geniculate nucleus, the visual cortex and the afferent pathway (Nucci et al., 2003, 2013a; Martucci et al., 2014). In particular, the atrophy of neurons in the lateral geniculate nucleus and the visual cortex has been documented in primates with experimental glaucoma (Yücel et al., 2000, 2003; Weber et al., 2000). The involvement of the CNS was also described in humans with glaucoma, ex vivo, by Chaturvedi et al. (1993) and then confirmed, both histologically and using magnetic resonance, by Gupta et al. (2006, 2009) and by Dai et al. (2011). In this regard, our group using Magnetic Resonance Imaging (MRI) with diffusion tensor (DT-MRI) confirmed that patients with glaucoma show alterations not only of the optic nerve, but also of the optic radiations (Garaci et al., 2009). DT-MRI parameters at the level of the optic nerve showed a good correlation not only with the progression of the disease, but also with morphological features of the optic nerve head and the retinal nerve fiber layer (RNFL) thickness assessed by GDx-VCC, Heidelberg Retinal Tomography III and Stratus Optical Coherence Tomography (Nucci et al., 2012). Moreover, DT-MRI parameters analysis showed a different pattern of diffusion of the disease that in early glaucoma the neuronal damage resulted predominantly located in the proximal portions of the optic nerve, at the level of retro-laminar region, while in the advanced stages both the proximal and distal portions of the nerves were affected (Bolacchi et al., 2012).

Although conventional neuroimaging still plays an important role, advanced MR techniques, such as diffusion tensor imaging, functional imaging, and magnetic resonance spectroscopy, allow to identify in vivo and noninvasively changes along the visual pathway in both early and late stages of the disease (Garaci et al., 2015; Mastropasqua et al., 2015). In this regard, a recent study using multimodal MRI and whole-brain explorative voxelwise analyses, showed the occurrence, in patients with advanced glaucoma, of structural and functional changes not limited to the white matter tracts of the visual pathway, but also extended to nonvisual areas of the central nervous system, such as superior longitudinal fascicle, anterior thalamic radiations, corticospinal tract, middle cerebellar peduncle, frontoparietal cortex, hippocampus and cerebellar cortex (Frezzotti et al., 2014).

\section{Glaucoma and Neurodegenerative diseases}

Glaucoma is a complex neurodegenerative disease whose pathogenesis is still not entirely known.

Recent evidence reports that some of the cases we actually define as glaucoma may be the expression of neurodegenerative or vascular diseases of the central nervous system only partially or even completely unaffected by ocular risk factors (Nucci et al., 2015; Danesh-Meyer and Levin, 2015).

Epidemiological studies reported numerous evidences of increased prevalence of glaucoma in patients affected by Alzheimer Disease (AD). In this regard, Bayer et al. (2002a) firstly revealed that $24.5 \%$ of $\mathrm{AD}$ patients had possible diagnosis of glaucoma compared to the $6.5 \%$ of control and then confirmed, in another study, an occurrence rate of glaucoma in the $25.9 \%$ of AD patients compared to the $5.2 \%$ of matched controls (Bayer et al., 2002b). Likewise, Tamura et al. (2006) described a $23.8 \%$ prevalence of primary open angle glaucoma in $\mathrm{AD}$ patients with respect of the 9.9\% of the controls. In accordance, Cesareo et al. (2015b) showed that the frequency of glaucoma-like alterations was four times higher $(27.5 \%)$ in $\mathrm{AD}$ patients than that of controls (7.5\%). Interestingly, in these studies intraocular pressure values were not statistically different between groups, thus suggesting that AD subjects may be more vulnerable to develop clinical pictures similar to those found in glaucoma even if exposed to IOP levels considered in the normal range.

Pelletier et al. (2014), recently confirmed these results showing a higher prevalence of glaucoma in adults with dementia of the Alzheimer's type or dementia with vascular contribution when compared to controls.

In agreement with the epidemiological data, recent studies showed the presence of altered biomarkers of AD, such as amyloid- $\beta$, tau, and phosphorylated tau in animals with experimental glaucoma or in affected patients, supporting the hypothesis of a common pathogenesis between the diseases (Guo et al., 2007; Gupta et al., 2008; Inoue et al., 2013; Nucci et al., 2011, 2015). Moreover, Wostyn et al. (2008) hypothesized that the cerebrospinal fluid pressure (CSFP) may be responsible for the greater risk of glaucoma reported in patients with AD. In fact, it has been suggested that in glaucoma an imbalance between the CSFP and the IOP over the lamina cribrosa, caused by reduced levels of CSFP, may cause a displacement of the fibers damaging the RGCs. Interestingly, reduced CSFP has been observed in a small percentage of patients with $\mathrm{AD}$ (Silverberg et al., 2006). In addition, Killer et al. (2008a) hypothesized that due to altered CSF circulatory dynamics and being surrounded by CSF contained in the subarachnoid space, the optic nerve, might be exposed, to the neurotoxic molecules released by Alzheimer's disease, such as $\beta$-amyloid- and tau, with a cytotoxic effect (Killer et al., 2008a, 2008b; Wostyn et al., 2013).

Finally, the reduction of beclin 1, a gene product involved in the autophagy machinery, has been recently proposed as a potential contributing factor in neurodegenerative diseases, such as AD. Accordingly, recent studies show that autophagy constitutively takes place in RGC and acute IOP elevation, causes autophagy derangement and RGC death (Jaeger and Wyss-Coray, 2009; Rodriguez-Muela and Boya, 2012; Russo et al., 2011, 2013a), thus suggesting that in both diseases there may be an alteration of the autophagic pathway.

As for AD there is evidence of a possible connection between Parkinson Disease (PD) and glaucoma. In particular, Bayer et al. (2002a) and Nowacka et al. (2014) reported a higher incidence of glaucoma in PD. Interestingly, in these studies PD patients had normal or significantly lower IOP values compared to controls. This data was also confirmed by Yenice et al. (2008) and Tsironi et al. (2012), which reported a higher prevalence of glaucomatous visual field defects in patients with PD. These alterations have been subsequently corroborated by several studies reporting a significantly reduced RNFL thickness in patients with PD (Inzelberg et al., 2004; Altinta,ş et al., 2008; Eraslan et al., 2015).

Another possible connection has been suggested between Leber Heraditary Optic Neuropathy (LHON) and glaucoma (Nucci et al., 2013b; Thouin et al., 2013). In this regard, optic nerve head cupping (Mashima et al., 2003; Inagaki et al., 2006) and delayed VF loss (Newman, 1993) have been described in people carrying mtDNA mutation. This suggests that raised IOP could be a risk factor for visual loss in carriers of LHON mutations.

Interestingly, several reports suggested a possible connection also between glaucomatous damage and cerebrovascular alterations. In particular, drops in regional cerebral blood flow, especially in those areas of the visual system situated in watershed areas, may induce infarctions that lead to axonal and glial degeneration, as well as to the development of the typical alterations of glaucoma (Pantoni and Garcia, 1997; Momjian-Mayor et al., 2005; Leung et al., 2009). Hence, the vascular alterations, which are IOP independent, and the resulting ischemic phenomena, may induce and/or synergize with the glaucomatous degenerative process. 


\section{Glaucoma and neuroprotection}

Overall, these data support the hypothesis that glaucomatous damage is not limited to the eye, but it also involves the central visual pathways. These alterations may be either the consequence of the anterograde transynaptic diffusion of death signals prompted by the RGCs, or the result of a retrograde mechanism of transduction induced by neurodegenerative diseases that primarily affect the CNS (Nucci et al., 2013a). In view of this, pharmacological treatments targeting IOP may not be sufficient to control the disease, thus indicating the need of novel neuroprotective strategies aimed to prevent, slow down or stop the RGC loss.

Several animal models are available to reproduce the apoptotic death of RGCs and to test the neuroprotective potential of drugs. The models differ regarding the type of applied insult that varies from short to medium-term elevation of IOP, to axonal injury (e.g. crushing or resection of the optic nerve) and induction of retinal hypoxia/ischemia (see Johnson and Tomarev, 2010). It has to be stressed that none of them entirely recapitulate the features of glaucoma neurodegeneration and therefore drugs showing neuroprotective properties should be tested in more than one model in order to validate the translational value of the data.

The hostile environment that leads to glaucoma-associated death of RGCs following a still undetermined trigger, is characterized by alteration of several pathways including neurotrophin signaling, oxidative stress, excitotoxicity, mitochondrial dysfunction, protein misfolding, ischemic events, autoimmunity and neuroinflammation (Baltmr et al., 2010). Therefore, each of these components might represent a potential target for achieving neuroprotection.

\subsection{Anti-excitotoxicity strategies}

Several studies suggested that excitotoxicity plays a key role in RGC degeneration associated with glaucoma through the overactivation of both N-methyl-D-aspartate (NMDA) and non-NMDA glutamate receptors (Nucci et al., 2005b; Russo et al., 2009). Indeed, despite the doubts that have been raised regarding the effective role of glutamate in glaucoma (see Salt and Cordeiro, 2006), several authors reported neuroprotection following treatment with NMDA and non-NMDA antagonists in experimental models of RGC death (Sucher et al., 1997; Adachi et al., 1998; Nucci et al., 2005b). Accordingly, blocking NO synthase (NOS), an enzyme involved in the excitotoxic cascade, by systemic pretreatment with the non-selective inhibitor L-NAME, minimized RGC loss (Nucci et al., 2005b).

Quite interestingly, modulation of the Akt pathway seems to be implicated in the neuroprotection afforded by NMDA receptor blockade (Russo et al., 2011).

Although the literature reports conflicting data (Dreyer et al., 1996: Brooks et al., 1997; Levkovitch-Verbin et al., 2002; CarterDawson et al., 2002; Honkanen et al., 2003; Wamsley et al., 2005), increased vitreal glutamate concentrations have been demonstrated in experimental models of glaucoma (Louzada-Júnior et al., 1992; Adachi et al., 1998; Nucci et al., 2005b) and this can be associated with excitatory amino acid transporters (EEAT) dysfunction (Martin et al., 2002; Russo et al., 2013b).

Under acute retinal ischemia, the glial glutamate-aspartate transporter (GLAST) showed a reduced efficiency leading to extracellular glutamate accumulation (Barnett et al., 2001) and Naskar et al. (2000) reported a reduction of GLAST expression in glaucomatous eyes. Vice versa, no significant change in GLAST expression was observed after optic nerve transection (Martin et al., 2002). Recently, using isolated retinal synaptosomes, our group reported changes in neuronal glutamate transporter subtype 1 (GLT-1) but not GLAST expression after retinal ischemia/ reperfusion (Russo et al., 2013b) supporting a role for neuronal transporters in these phenomena. Moreover, our results suggested the presence of an alternative, neuronal splice variant of GLT-1, induced in response to the ischemic damage (Russo et al., 2013b).

The potential involvement of the excitotoxic cascade in glaucoma-associated RGC death has prompted researchers to test the neuroprotective potential of drugs targeting this pathway.

\subsubsection{Neuroprotectants}

Since the 2000s several authors have shown neuroprotective effects on RGCs following treatment with memantine, an use-dependent blocker of the NMDA channel approved in Europe and USA for the treatment of Alzheimer's dementia. Gu et al. (2000) reported its ability to reduce RGC loss in rat after laser trabecular photocoagulation, and Hare et al. (2001) observed protective effects on visually-evoked cortical potential amplitude in monkey and RGC survival in rat. Likewise, WoldeMussie et al. (2002) reported memantine neuroprotection after optic nerve injury and in a chronic ocular hypertension model in rat. Further studies carried out by Hare et al. (2004a, 2004b) in primates confirmed the efficacy and safety of memantine. Lipton theorized that memantine could be a promising neuroprotective agent for the treatment of glaucoma since it preferentially blocks excessive NMDA receptor activity without interfering with normal synaptic transmission (Lipton, 2003, 2004). However, despite the positive results obtained from preclinical studies (Zhong et al., 2007; Hare and Wheeler, 2009; Ju et al., 2009), the clinical trial did not completely support the potential beneficial effects of the NMDA antagonist (see Sena and Lindsley, 2013).

Other compounds have shown neuroprotective properties in experimental models of glaucoma by interfering with excitotoxic mechanisms.

Brimonidine is an $\alpha-2$ adrenergic agonist clinically used for the treatment of glaucoma due to its ability of lowering IOP. Wheeler et al. (2003) have shown that treatment with brimonidine is associated with neuroprotective effects on RGCs loss in different experimental models of glaucoma. Accordingly, work by Villena et al. (2009) and Vidal et al. (2010) supported the retinal neuroprotective effect of brimonidine. In particular, Vidal et al. (2010) have shown that hypotensive drugs attenuate retinal gliosis. More recently, Jung et al. (2015) reported that brimonidine decreases RGC apoptosis upregulating EAAT1 and downregulating NMDA receptors.

Our group reported RGC neuroprotection elicited by $17 \beta$-estradiol in experimental retinal ischemia induced by transient increase of IOP (Russo et al., 2008a); the observed neuroprotection is associated with decreased vitreal glutamate levels and this might be the event preventing RGC death (Russo et al., 2008a). Accordingly, increased glutamate uptake prevents the death of RGCs (Pawlak et al., 2005).

Recently, Sakamoto et al. (2015) reported that $\mathrm{P} 2 \times 7$ receptor antagonists protect against NMDA-induced retinal injury in rat decreasing the number of terminal deoxynucleotidyl transferase dUTP nick end labeling-positive (TUNEL) cells. Moreover, Yanagisawa et al. (2015) reported that arundic acid, a glial modulating agent, reduces RGC death by increasing GLAST expression in a model of normal tension glaucoma. Furthermore, valproic acid, a drug widely prescribed for treatment of epilepsy, mood disorders, migraines, and neuropathic pain, shows protective effects and reduced RGC death induced by NMDA intravitreal injection likely stimulating brain-derived neurotrophic factor up-regulation in Müller glial cells (Kimura et al., 2015).

Neuropeptide $Y$ receptors activation also protects retinal cells against excitotoxicity in rat by the activation of protein kinase $\mathrm{A}$ and p38K (Santos-Carvalho et al., 2013). Y2 and Y4 receptors are 
involved in the protective effect of neuropeptide Y against necrotic, while Y5 against necrotic and apoptotic cell death induced by glutamate (Santos-Carvalho et al., 2013).

Interestingly, in 2012, Froger and colleagues reported a protective effect of the amino acid taurine against excitotoxicity showing increase RGC survival in vivo and in vitro and suggesting that enriched taurine nutrition can directly promote RGC survival (Froger et al., 2012). Moreover, nafamostat mesilate, a serine protease inhibitor showed protection against NMDA-induced neuronal and vascular damage in rat retinas (Tsuda et al., 2012).

\subsubsection{Antioxidant agents}

Oxidative stress, a condition that takes place when generation of reactive oxygen species (ROS) exceed the antioxidant capacity of the cell. Several evidence suggest a key role for oxidative stress in RGC loss caused by glutamate-induced retinal damage (Luo et al., 2001; Nucci et al., 2005b; Tezel, 2006) and therefore free radical scavengers can be used to prevent cell death under excitotoxic conditions (Lipton and Rosenberg, 1994). Inhibition of fundamental functions in mitochondria leading to defective energy metabolism is one of the detrimental effects generated by free radical species (Patel et al., 1996; Duchen, 2000). Using high IOPinduced ischemia, our group reported that coenzyme Q10, an essential cofactor of the electron transport chain, afforded retinal neuroprotection after topical application (Nucci et al., 2007a; Russo et al., 2008b). Interestingly, using microdialysis technique we also observed that coenzyme Q10 is able to prevent vitreal glutamate increase minimizing RGC death (Nucci et al., 2007a). Overactivation of glutamate receptors leads to formation of the permeability transition pore (PTP) and, consequently, to RGC apoptotic death (see Kroemer and Reed, 2000). Interestingly, coenzyme Q10 has been shown to inhibit apoptosis by maintaining PTP in the closed conformation via a mechanism independent from free radical scavenging (Papucci et al., 2003). Therefore, it can be hypothesized that coenzyme Q10 acts on mitochondrial energy metabolism and this is reflected on EAATs function.

Interestingly, Lee et al. (2014) reported that a diet supplemented with coenzyme Q10 protects against excitotoxicity and oxidative stress damage in an experimental model of glaucoma in DBA/2J mice. In particular, coenzyme Q10 promotes RGC survival by modulating Bax and Bad protein expression and by preserving mitochondrial DNA content and mitochondrial transcription factor A/oxidative phosphorylation complex IV protein expression (Lee et al., 2014). These same authors also reported that brimonidine protects RGCs against excitotoxicity-induced oxidative stress in rat. Particularly, the $\alpha-2$ adrenergic agonist preserved the expression of mitochondrial transcription factor A and oxidative phosphorylation complex in ischemic retina (Lee et al., 2012).

\subsubsection{Cannabinoids}

Experimental findings suggest that cannabinoids also may minimize excitotoxic RGC damage. Although, several studies have shown that topical administration of cannabinoids reduces IOP (Pate et al., 1995; Laine et al., 2001; Chien et al., 2003) by modulating both production and drainage of aqueous humor (Chien et al., 2003; Njie et al., 2006) a number of studies reported that cannabinoids exert neuroprotective effects in the eye against glutamate-induced excitotoxicity (Jarvinen et al., 2002; Crandall et al., 2007; Nucci et al., 2007b, 2008; Duncan et al., 2011), with potential implications for the treatment of glaucoma.(Tomida et al., 2004; Yazulla, 2008). Interestingly, some studies suggested that inhibition of glutamate release represents a key mechanism involved in neuroprotection mediated by the cannabinoid system (Braida et al., 2000; Sinor et al., 2000; Marsicano et al., 2003; Gobira et al., 2015; Lin et al., 2015). In 2007, our group using an animal model of acute glaucoma reported that inhibition of fatty acid amide hydrolase (FAAH) or administration of metanandamide, a stable analogue of anandamide, minimize RGC loss caused by ischemia/reperfusion and that MK801, a noncompetitive NMDA receptors antagonist, controls anandamide degradation through FAAH (Nucci et al., 2007b). Accordingly, it is likely that excitotoxic stimuli may affect the metabolism of endocannabinoids in the mammalian retina. We also suggested that FAAH inhibitors like URB597 might become useful pharmacologic tools to counteract RGC damage (Nucci et al., 2007b). Consistent with these findings, recently, Slusar et al. (2013) reported that URB597 increases RGCs survival following optic nerve axotomy and this neuroprotective effect occurs primarily via activation of type 1 cannabinoid receptors $\left(\mathrm{CB}_{1}\right)$. Accordingly, several studies suggested a key role for $\mathrm{CB}_{1}$ receptors activation in cannabinoid neuroprotection. In agreement, $\mathrm{CB}_{1} \mathrm{R}$-knockout mice have been reported to be more sensitive to inflammatory and excitotoxic insults than control animals (Pryce et al., 2003) and activation of $\mathrm{CB}_{1}$ receptors elicits inhibitory effects by reducing glutamate release (Howlett et al., 2004; Lin et al., 2015). Interestingly, Gobira et al. (2015) suggested that cannabidiol, a non-psychotomimetic constituent of Cannabis sativa, shows neuroprotection reducing glutamate release through activation of mTOR pathway. Cannabidiol and $\Delta 9$-tetrahydrocannabinol also have been shown to prevent retinal neurotoxicity by reducing the formation of NO after in vivo intravitreal injection of NMDA (El-Remessy et al., 2003). In addition, more recently, Duncan et al. (2011) reported that linoleoylethanolamine protects neurons in the RGC layer against glutamate excitotoxicity in ex-vivo retina cultures reducing apoptosis.

\subsection{Endogenous pro-survival pathways and neuroprotection}

It is conceivable that endogenous protective responses are activated, at least during the early stage of the disease, in order to counteract and balance the stressing milieu; accordingly, death of RGCs can be envisaged as the result of the failure/dysfunction of autoprotective responses.

The phosphoinositide-3 kinase (PI3K) pathway (Brazil and Hemmings, 2001) is physiologically activated by several neurotrophins, such as brain derived neurotrophic factor (BDNF), insulin like growth factor I (IGF-I), nerve growth factor (NGF) (Kaplan and Miller, 2000), turning on the protein kinase B (PKB), also known as Akt, a serine/threonin kinase endowed with pro-survival and antiapoptotic effects (Franke et al., 2003).

Several studies have shown the activation of the PI3K/Akt pathway in response to glaucoma-related experimental insult like excitotoxicity (Manabe and Lipton, 2003; Nakazawa et al., 2005), ocular hypertension (Kanamori et al., 2004; Kim and Park, 2005; Levkovitch-Verbin et al., 2007), retinal ischemia induced by optic nerve clumping (Nakazawa et al., 2003) or transient elevation of IOP (Russo et al., 2008a). Activation of Akt is one of the mechanisms through which administration of neurotrophins, such as IGFI, BDNF or erythropoietin (EPO), prevents RGC apoptosis following optic nerve axotomy (Klocker et al., 2000; Nakazawa et al., 2002; Weishaupt et al., 2004). Similarly, substances of natural origin like crocin, a pharmacologically active component of saffron (Crocus sativus L.) or forskolin ( 7 beta-acetoxy-8,13-epoxy- 1 alpha, 6 beta, 9 alpha-trihydroxy-labd-14-ene-11-one), the main active compound extracted from the roots of Coleus forskohlii, prevent RGC apoptosis induced by retinal ischemia/reperfusion by acting on the PI3K/Akt signaling pathway (Qi et al., 2013; Russo et al., 2015a).

The reported increase of RGC death observed in PI3K inhibitors-treated retinas following optic nerve clamping or retinal ischemia further support the neuroprotective role for the endogenous activation of this pathway (Nakazawa et al., 2003; Huang et al., 2008; Russo et al., 2008a).

It has been shown that the neuroprotection afforded by 
treatment with neurotrophic factors is potentiated by the simultaneous administration of substances with antioxidant activities. Indeed, association of BDNF with a non-specific free radical scavenger, N-tert-butyl-(2-sulfophenyal)-nitrone ((s-PBN)), increased survival of RGCs in ocular hypertensive eyes (Ko et al., 2000). Furthermore, BDNF-mediated neuroprotection was potentiated by L-NAME, a NOS inhibitor, in axotomized RGCs (Klocker et al., 1998). Similarly, our group has recently shown that when forskolin is combined with homotaurin and L-carnosine, substances endowed with antioxidant and neuromodulatory properties, respectively, produces a more pronounced neuroprotective effect on RGC survival following transient IOP increase and this is partly mediated by activation of the PI3K/Akt pathway (Russo et al., 2015a).

Autophagy is an evolutionarily conserved process by which eukaryotic cells regulate the turnover of long-lived proteins and cytoplasmic organelles and it gained recent attention for its involvement in the pathophysiology of several, including neurodegenerative, diseases (Cuervo et al., 2004; Glick et al., 2010). Most evidence suggest a neuroprotective role of this pathway that would help neurons to get rid of altered and damaged proteins and protein aggregates while degrading endogenous components in order to recycle the metabolic by-products (i.e. amino acids, fatty acids, nucleotides and others) for new synthesis. Autophagy is constantly active in each cell supporting homeostatic functions, but it can also act as adaptive catabolic process in response to several stimuli (Kourtis and Tavernarakis, 2009). mTOR is the main negative regulator of the process which is orchestrated by 36 different autophagy-related genes (Atg) coordinating the formation of a double membrane structure (autophagosome) and its fusion with lysosomes where the cargo is degraded (Levine and Klionsky, 2004; Nakatogawa et al., 2009).

Growing evidence supports the involvement of the autophagic process in the pathophysiology of glaucoma and several studies reported a dysregulation, either toward induction or inhibition, of the pathway (recently reviewed in Russo et al., 2013a, 2015b).

Upregulation of Atg proteins were reported following optic nerve transection by Kim et al. (2008). Similarly, autophagosome accumulation was shown in the retina of GFP-LC3 mice subjected to optic nerve axotomy (Rodriguez-Muela et al., 2012). Accordingly, $\mathrm{Ca}^{2+}$-dependent accumulation of LC3-positive autophagosomes was also detected in RGC axons following optic nerve crush (Knoferle et al., 2010). However, contradictory results were reported regarding the role attributed to autophagy induction following optic nerve injuries. Indeed, while the data reported by Rodriguez-Muela et al. (2012) showed increased RGC survival after treatment of axotomixed mice with rapamycin, a mTOR inhibitor widely used to induce autophagy, Knoferle et al. (2010) reported that inhibition of the pathway by intravitreal injection of 3-methyladenine (3-MA) delayed the neurodegenerative process.

Downregulation of the autophagosome-associated protein LC3II and proteolytic cleavage of beclin-1, a protein essential in the initial step of the process, have been associated with RGC death induced by retinal ischemia/reperfusion in rats (Russo et al., 2011). However, in a similar experimental model, upregulation of LC3II and ultrastructural features of double and multi-membrane acidic vesicles (autophagosomes) were also reported (Piras et al., 2011; Wei et al., 2015).

Autophagy was induced in a chronic hypertensive glaucoma model induced by laser photocoagulation in primates (Deng et al., 2013) and increased number of autophagosomes and of autophagy related proteins, LC3II and beclin-1, were detected in soma and dendrites of RGCs from rats subjected to episcleral vein cauterization (Park et al., 2012). In the latter study, pharmacological inhibition of autophagy by 3-MA increased cell survival in the ganglion cell layer suggesting a protective role for autophagy (Park et al., 2012).

Accumulation of autophagic vacuoles and increased level of the autophagic substrate p62 were detected in unmyelinated axons suggesting an impairment of the process following laser-induced IOP elevation (Kitaoka et al., 2013). Under this experimental condition treatment with the autophagy inducer rapamycin exerted protective effects, while autophagy inhibition exacerbated axonal damage (Kitaoka et al., 2013). Vice versa, in the same glaucoma model induced by laser photocoagulation, Su et al. (2014) reported a significant reduction of RGC loss following treatment with rapamycin.

\subsection{RGCs subtypes and neuroprotection}

In a recent paper, Vidal-Sanz et al., (2015) described a new subtype of retinal RGC defined intrinsically photosensitive RGCs (ipRGCs). These cells, expressing photopigment melanopsin, detects light, behave like photoreceptors and are involved in several non-image-forming visual functions. In particular, they regulate the melatonin release, the pupillary control, and play a major role in synchronizing circadian rhythms to the 24-h light/dark cycle.

Interestingly, animal models of ocular hypertension (OHT) induced by laser-photocoagulation (Valiente-Soriano et al., 2015) indicated, although with a different pattern, a similar proportion of cellular death in the general population of RGCs (Brn3a+ RGCs) and the ipRGCs melanopsin-expressing type $\left(\mathrm{m}^{+} \mathrm{RGCs}\right)$. Brn3a ${ }^{+}$RGCs, in fact, showed a sectorial damage while $\mathrm{m}^{+} \mathrm{RGCs}$, revealed a diffuse pattern of loss. Moreover, the intravitreal injection of BDNF induced a different neuroprotective response indicating that Brn3a ${ }^{+}$RGCs are amenable to BDNF while $\mathrm{m}^{+} \mathrm{RGCs}$ are not.

Overall, this data shows that even in the same cellular population some subtypes may differently respond to neuroprotective molecules of well-known efficacy, suggesting how in the assessment of the effectiveness of these molecules is also important the evaluation of the target cellular type.

\section{Conclusion}

Glaucoma is still a leading cause of blindness in the world. As highlighted in the review numerous evidences indicate that the disease also involves the central areas of the visual system. There are also data indicating that glaucoma presents common aspects with other neurodegenerative or vascular diseases of the central nervous system. Altogether, these data emphasize the need to identify new therapeutic strategies based on neuroprotection. The results presented here confirm that numerous molecules have been shown to be effective in preventing neuronal damage in experimental models of glaucoma. However, to date, there are no sufficient clinical evidence confirming the efficacy of such molecules in patients with glaucoma.

\section{Acknowledgements}

Partial financial support from PRIN (Project protocol 20109MXHMR_008) and from University of Calabria (ex quota $60 \%)$ are gratefully acknowledged.

\section{References}

Adachi, K., Kashii, S., Masai, H., Ueda, M., Morizane, C., Kaneda, K., Kume, T., Akaike, A., Honda, Y., 1998. Mechanism of the pathogenesis of glutamate neurotoxicity in retinal ischemia. Graefes Arch. Clin. Exp. Ophthalmol. 236 (10), 766-774. 
Altintaş, O., Işeri, P., Ozkan, B., Cağlar, Y., 2008. Correlation between retinal morphological and functional findings and clinical severity in Parkinson's disease. Doc. Ophthalmol. 116 (2), 137-146.

Baltmr, A., Duggan, J., Nizari, S., Salt, T.E., Cordeiro, M.F., 2010. Neuroprotection in glaucoma - is there a future role? Exp. Eye Res. 91, 554-566.

Barnett, N.L., Pow, D.V., Bull, N.D., 2001. Differential perturbation of neuronal and glial glutamate transport systems in retinal ischaemia. Neurochem Int. 39 (4), 291-299.

Bayer, A.U., Keller, O.N., Ferrari, F., Maag, K.P., 2002a. Association of glaucoma with neurodegenerative diseases with apoptotic cell death: Alzheimer's disease and Parkinson's disease. Am. J. Ophthalmol. 133, 135-137.

Bayer, A.U., Ferrari, F., Erb, C., 2002b. High occurrence rate of glaucoma among patients with Alzheimer's disease. Eur. Neurol. 47 (3), 165-168.

Bolacchi, F., Garaci, F.G., Martucci, A., Meschini, A., Fornari, M., Marziali, S., Mancino, R. Squillaci, E., Floris, R., Cerulli, L., Simonetti, G., Nucci, C., 2012. Differences between proximal versus distal intraorbital optic nerve diffusion tensor magnetic resonance imaging properties in glaucoma patients. Invest. Ophthalmol. Vis. Sci. 53 (7), 4191-4196.

Braida, D., Pozzi, M., Sala, M., 2000. CP 55940 protects against ischemia-induced electroencephalographic flattening and hyperlocomotion in Mongolian gerbils. Neurosci. Lett. 296, 69-72.

Brazil, D.P., Hemmings, B.A., 2001. Ten years of protein kinase B signalling: a hard Akt to follow. Trends Biochem. Sci. 26, 657-664.

Brooks, D.E., Garcia, G.A., Dreyer, E.B., Zurakowski, D., Franco-Bourland, R.E., 1997. Vitreous body glutamate concentration in dogs with glaucoma. Am. J. Vet. Res. 58, 864-867.

Carter-Dawson, L., Crawford, M.L., Harwerth, R.S., Smith 3rd, E.L., Feldman, R., Shen, F.F., Mitchell, C.K., Whitetree, A., 2002. Vitreal glutamate concentration in monkeys with experimental glaucoma. Invest. Ophthalmol. Vis. Sci. 43 (8), 2633-2637.

Cedrone, C., Mancino, R., Cerulli, A., Cesareo, M., Nucci, C., 2008. Epidemiology of primary glaucoma: prevalence, incidence, and blinding effects. Prog. Brain Res. 173, 3-14.

Cedrone, C., Mancino, R., Ricci, F., Cerulli, A., Culasso, F., Nucci, C., 2012. The 12-year incidence of glaucoma and glaucoma-related visual field loss in Italy: The Ponza eye study. J. Glaucoma 21 (1), 1-6.

Cesareo, M., Ciuffoletti, E., Ricci, F., Missiroli, F., Giuliano, M.A., Mancino, R., Nucci, C. 2015a. Visual disability and quality of life in glaucoma patients. Prog. Brain Res. 221, 359-374.

Cesareo, M., Martucci, A., Ciuffoletti, E., Mancino, R., Cerulli, A., Sorge, R.P., Martorana, A. Sancesario, G., Nucci, C., 2015b. Association between Alzheimer's disease and glaucoma: a study based on heidelberg retinal tomography and frequency doubling technology perimetry. Front. Neurosci. http://dx doi.org/10.3389/fnins.2015.00479

Chaturvedi, N., Hedley-Whyte, E.T., Dreyer, E.B., 1993. Lateral geniculate nucleus in glaucoma. Am. J. Ophthalmol. 116, 182-188.

Chien, F.Y., Wang, R.F., Mittag, T.W., Podos, S.M., 2003. Effect of WIN 55212-2, a cannabinoid receptor agonist, on aqueous humor dynamics in monkeys. Arch. Ophthalmol. 121, 87-90.

Crandall, J., Matragoon, S., Khalifa, Y.M., Borlongan, C., Tsai, N.T., Caldwell, R.B., Liou, G.I., 2007. Neuroprotective and intraocular pressure-lowering effects of (-)Delta9-tetrahydrocannabinol in a rat model of glaucoma. Ophthalmic Res. 39 (2), 69-75.

Cuervo, A.M., Stefanis, L., Fredenburg, R., Lansbury, P.T., Sulzer, D., 2004. Impaired degradation of mutant alpha-synuclein by chaperone-mediated autophagy. Science 305, 1292-1295.

Dai, H., Mu, K.T., Qi, J.P., Wang, C.Y., Zhu, W.Z., Xia, L.M., Chen, Z.Q., Zhang, H., Ai, F., Morelli, J.N., 2011. Assessment of lateral geniculate nucleus atrophy with 3T MR imaging and correlation with clinical stage of glaucoma. AJNR Am. J. Neuroradiol. 32, $1347-1353$.

Danesh-Meyer, H.V., Levin, L.A., 2015. Glaucoma as a neurodegenerative disease. J. Neuroophthalmol. 35 (1), S22-S28.

Deng, S., Wang, M., Yan, Z., Tian, Z., Chen, H., Yang, X., Zhuo, Y., 2013. Autophagy in retinal ganglion cells in a rhesus monkey chronic hypertensive glaucoma model. PloS One 8 , e77100.

Dreyer, E.B., Zurakowski, D., Schumer, R.A., Podos, S.M., Lipton, S.A., 1996. Elevated glutamate levels in the vitreous body of humans and monkeys with glaucoma. Arch. Ophthalmol. 114, 299-305.

Duchen, M.R., 2000. Mitochondria and calcium: from cell signalling to cell death. J. Physiol. 529 (1), 57-68.

Duncan, R.S., Xin, H., Goad, D.L., Chapman, K.D., Koulen, P., 2011. Protection of neurons in the retinal ganglion cell layer against excitotoxicity by the N-acylethanolamine, N-linoleoylethanolamine. Clin. Ophthalmol. 5, 543-548.

El-Remessy, A.B., Khalil, I.E., Matragoon, S., Abou-Mohamed, G., Tsai, N.J., Roon, P., Caldwell, R.B., Caldwell, R.W., Green, K., Liou, G.I., 2003. Neuroprotective effect of Delta9-tetrahydrocannabinol and cannabidiol in N-methyl-D-aspartate-induced retinal neurotoxicity: involvement of peroxynitrite. Am. J. Pathol. 163, 1997-2008.

Eraslan, M., Balci, S.Y., Cerman, E., Temel, A., Suer, D., Elmaci, N.T., 2015. Comparison of optical coherence tomography findings in patients with primary open-angle glaucoma and parkinson disease. J. Glaucoma (Epub Ahead of Print).

Franke, T.F., Hornik, C.P., Segev, L., Shostak, G.A., Sugimoto, C., 2003. PI3K/Akt and apoptosis: size matters. Oncogene 22, 8983-8998.

Frezzotti, P., Giorgio, A., Motolese, I., De Leucio, A., Iester, M., Motolese, E., Federico, A., De Stefano, N., 2014. Structural and functional brain changes beyond visual system in patients with advanced glaucoma. PLoS One 9 (8), e105931.

Froger, N., Cadetti, L., Lorach, H., Martins, J., Bemelmans, A.P., Dubus, E., Degardin, J., Pain, D., Forster, V., Chicaud, L., Ivkovic, I., Simonutti, M., Fouquet, S., Jammoul, F., Léveillard, T., Benosman, R., Sahel, J.A., Picaud, S., 2012. Taurine provides neuroprotection against retinal ganglion cell degeneration. PLoS One 7 (10), e42017.

Garaci, F.G., Bolacchi, F., Cerulli, A., Melis, M., Spanò, A., Cedrone, C., Floris, R., Simonetti, G., Nucci, C., 2009. Optic nerve and optic radiation neurodegeneration in patients with glaucoma: in vivo analysis with 3-T diffusion-tensor MR imaging. Radiology 252, 496-501.

Garaci, F., Altobelli, S., Toschi, N., Mancino, R., Nucci, C., Schillaci, O., Floris, R., 2015. Brain imaging in glaucoma from clinical studies to clinical practice. Prog. Brain Res. 2015 (221), 159-175.

Group CN-TGS, 1998a. Comparison of glaucomatous progression between untreated patients with normal-tension glaucoma and patients with therapeutically reduced intraocular pressures. Am. J. Ophthalmol. 126 (4), 487-497.

Group CN-TGS, 1998b. The effectiveness of intraocular pressure reduction in the treatment of normal tension glaucoma. Am. J. Ophthalmol. 126 (4), 498-505.

Glick, D., Barth, S., Macleod, K.F., 2010. Autophagy: cellular and molecular mechanisms. J. Pathol. 221, 3-12.

Gobira, P.H., Vilela, L.R., Gonçalves, B.D., Santos, R.P., de Oliveira, A.C., Vieira, L.B., Aguiar, D.C., Crippa, J.A., Moreira, F.A., 2015. Cannabidiol, a Cannabis sativa constituent, inhibits cocaine-induced seizures in mice: Possible role of the mTOR pathway and reduction in glutamate release. Neurotoxicology 50, 116-121.

Gu, Z., Yamamoto, T., Kawase, C., Matsubara, M., Kawase, K., Sawada, A., Kitazawa, Y., 2000. Neuroprotective effect of N-methyl-D-aspartate receptor antagonists in an experimental glaucoma model in the rat. Nippon Ganka Gakkai Zasshi 104 (1), 11-16.

Guo, L., Salt, T.E., Luong, V., Wood, N., Cheung, W., Maass, A., Ferrari, G., Russo-Marie, F, Sillito, A.M., Cheetham, M.E., Moss, S.E., Fitzke, F.W., Cordeiro, M.F., 2007. Targeting amyloid- $\beta$ in glaucoma treatment. Proc. Natl. Acad. Sci. U.S.A. 104 (33), 13444-13449.

Gupta, N., Ang, L.,C., Noël de Tilly, L., Bidaisee, L., Yücel, L.H., 2006. Human glaucoma and neural degeneration in intracranial optic nerve, lateral geniculate nucleus, and visual cortex. Br. J. Ophthalmol. 90, 674-678.

Gupta, N., Fong, J., Ang, L.C., Yücel, Y.H., 2008. Retinal tau pathology in human glaucomas. Can. J. Ophthalmol. 43 (1), 53-60.

Gupta, N., Greenberg, G., de Tilly, L.N., Gray, B., Polemidiotis, M., Yücel, Y.H., 2009. Atrophy of the lateral geniculate nucleus in human glaucoma detected by magnetic resonance imaging. Br. J. Ophthalmol. 93, 56-60.

Hare, W., WoldeMussie, E., Lai, R., Ton, H., Ruiz, G., Feldmann, B., Wijono, M., Chun, T., Wheeler, L., 2001. Efficacy and safety of memantine, an NMDA-type open-channel blocker, for reduction of retinal injury associated with experimental glaucoma in rat and monkey. Surv. Ophthalmol. 45 (3), S295-S296.

Hare, W.A., WoldeMussie, E., Lai, R.K., Ton, H., Ruiz, G., Chun, T., Wheeler, L., 2004a. Efficacy and safety of memantine treatment for reduction of changes associated with experimental glaucoma in monkey, I: Functional measures. Invest. Ophthalmol. Vis. Sci. 45 (8), 2625-2639.

Hare, W.A., WoldeMussie, E., Weinreb, R.N., Ton, H., Ruiz, G., Wijono, M., Feldmann, B., Zangwill, L., Wheeler, L., 2004b. Efficacy and safety of memantine treatment for reduction of changes associated with experimental glaucoma in monkey, II: Structural measures. Invest. Ophthalmol. Vis. Sci. 45, 2640-2651.

Hare, W.A., Wheeler, L., 2009. Experimental glutamatergic excitotoxicity in rabbit retinal ganglion cells: block by memantine. Invest. Ophthalmol. Vis. Sci. 50 (6), 2940-2948.

Heijl, A. Leske, M.C., Bengtsson, B., Hyman, L., Bengtsson, B., Hussein, M., Early Manifest Glaucoma Trial Group, 2002. Reduction of intraocular pressure and glaucoma progression: results from the Early Manifest Glaucoma Trial. Arch. Ophthalmol. 120 (10), $1268-1279$.

Honkanen, R.A., Baruah, S., Zimmerman, M.B., Khanna, C.L., Weaver, Y.K., Narkiewicz, J., Waziri, R., Gehrs, K.M., Weingeist, T.A., Boldt, H.C., Folk, J.C., Russell, S.R., Kwon, Y.H. 2003. Vitreous amino acid concentrations in patients with glaucoma undergoing vitrectomy. Arch. Ophthalmol. 121 (2), 183-188.

Howlett, A.C., Breivogel, C.S., Childers, S.R., Deadwyler, S.A., Hampson, R.E., Porrino, L.J. 2004. Cannabinoid physiology and pharmacology: 30 years of progress. Neuropharmacology 47, 345-358.

Huang, Y., Cen, L.P., Luo, J.M., Wang, N., Zhang, M.Z., van Rooijen, N., Pang, C.P., Cui, Q., 2008. Differential roles of phosphatidylinositol 3-kinase/akt pathway in retinal ganglion cell survival in rats with or without acute ocular hypertension. Neuroscience 153, 214-225.

Inagaki, Y., Mashima, Y., Fuse, N., Ohtake, Y., Fujimaki, T., Fukuchi, T., Glaucoma Gene Research Group, 2006. Mitochondrial DNA mutations with Leber's hereditary optic neuropathy in Japanese patients with open-angle glaucoma. Jpn. J. Ophthalmol. 50 (2), 128-134.

noue, T., Kawaji, T., Tanihara, H., 2013. Elevated levels of multiple biomarkers of Alzheimer's disease in the aqueous humor of eyes with open-angle glaucoma. Invest. Ophthalmol. Vis. Sci. 54 (8), 5353-5358.

Inzelberg, R., Ramirez, J.A., Nisipeanu, P., Ophir, A., 2004. Retinal nerve fiber layer thinning in Parkinson disease. Vis. Res. 44, 2793-2797.

Jarvinen, T., Pate, D.W., Laine, K., 2002. Cannabinoids in the treatment of glaucoma. Pharm. Ther. 95 (2), 203-220.

Jaeger, P.A., Wyss-Coray, T., 2009. All-you-can-eat: autophagy in neurodegeneration and neuroprotection. Mol. Neurodegener. 4,16.

Johnson, T.V., Tomarev, S.I., 2010. Rodent models of glaucoma. Brain Res. Bull. 81 (2-3), 349-358.

Ju, W.K., Kim, K.Y., Angert, M., Duong-Polk, K.X., Lindsey, J.D., Ellisman, M.H., Weinreb, R N., 2009. Memantine blocks mitochondrial OPA1 and cytochrome c release and subsequent apoptotic cell death in glaucomatous retina. Invest. Ophthalmol. Vis. Sci. 50 (2), 707-716.

Jung, K.I., Kim, J.H., Park, C.K., 2015. $\propto 2$-Adrenergic modulation of the glutamate recepto and transporter function in a chronic ocular hypertension model. Eur. J. Pharm. 15 (765), 274-283.

Kanamori, A., Nakamura, M., Nakanishi, Y., Nagai, A., Mukuno, H., Yamada, Y., Negi, A., 2004. Akt is activated via insulin/IGF-1 receptor in rat retina with episcleral vein cauterization. Brain Res. 1022, 195-204.

Kaplan, D.R., Miller, F.D., 2000. Neurotrophin signal transduction in the nervous system Curr. Opin. Neurobiol. 10, 381-391.

Kass, M.A., Heuer, D.K., Higginbotham, EJ. Johnson, C.A., Keltner, J.L, Miller, J.P. Parrish 2nd, R.K., Wilson, M.R., Gordon, M.O., 2002. The Ocular Hypertension Treatment Study: a randomized trial determines that topical ocular hypotensive medication delays or prevents the onset of primary open-angle glaucoma. Arch. Ophthalmol. 120 (6), 701-713.

Kersey, T., Clement, C.I., Bloom, P., Cordeiro, M.F., 2013. New trends in glaucoma risk, diagnosis \& management. Indian J. Med Res. 137 (4), 659-668.

Killer, H.E., Jaggi, G.P., Flammer, J., Miller, N.R., 2008a. Is open angle glaucoma caused by impaired cerebrospinal fluid circulation: around the optic nerve? Clin. Exp. Ophthalmol. 36, 308-311.

Killer, H.E., Flammer, J., Miller, N.R., 2008b. Glaucoma and cerebrospinal fluid pressure. Ophthalmology 115 (12), 2316-2317.

Kim, H.S., Park, C.K., 2005. Retinal ganglion cell death is delayed by activation of retinal 
intrinsic cell survival program. Brain Res. 1057, 17-28.

Kim, S.H., Munemasa, Y., Kwong, J.M., Ahn, J.H., Mareninov, S., Gordon, L.K., Caprioli, J., Piri, N., 2008. Activation of autophagy in retinal ganglion cells. J. Neurosci. Res. 86, $2943-2951$.

Kimura, A., Namekata, K., Guo, X., Noro, T., Harada, C., Harada, T., 2015. Valproic acid prevents NMDA-induced retinal ganglion cell death via stimulation of neuronal TrkB receptor signaling. Am. J. Pathol. 185 (3), 756-764.

Kitaoka, Y., Munemasa, Y., Kojima, K. Hirano, A., Ueno, S., Takagi, H., 2013. Axonal protection by Nmnat3 overexpression with involvement of autophagy in optic nerve degeneration. Cell Death Dis. 4, e860.

Klocker, N., Cellerino, A., Bahr, M., 1998. Free radical scavenging and inhibition of nitric oxide synthase potentiates the neurotrophic effects of brain-derived neurotrophic factor on axotomized retinal ganglion cells In vivo. J. Neurosci. 18, 1038-1046.

Klocker, N., Kermer, P., Weishaupt, J.H., Labes, M., Ankerhold, R., Bahr, M., 2000. Brainderived neurotrophic factor-mediated neuroprotection of adult rat retinal ganglion cells in vivo does not exclusively depend on phosphatidyl-inositol-3'-kinase/protein kinase B signaling. J. Neurosci. 20, 6962-6967.

Knoferle, J., Koch, J.C., Ostendorf, T., Michel, U., Planchamp, V., Vutova, P., Tonges, L., Stadelmann, C., Bruck, W., Bahr, M., Lingor, P., 2010. Mechanisms of acute axonal degeneration in the optic nerve in vivo. Proc. Natl. Acad. Sci. U.S.A. 107, 6064-6069.

Ko, M.L., Hu, D.N., Ritch, R., Sharma, S.C., 2000. The combined effect of brain-derived neurotrophic factor and a free radical scavenger in experimental glaucoma. Invest. Ophthalmol. Vis. Sci. 41, 2967-2971.

Kourtis, N., Tavernarakis, N., 2009. Autophagy and cell death in model organisms. Cell Death Differ. 16, 21-30.

Kroemer, G., Reed, J.C., 2000. Mitochondrial control of cell death. Nat. Med. 6 (5), 513-519.

Laine, K., Jarvinen, T., Savinainen, J., Laitinen, J.T., Pate, D.W., Jarvinen, K., 2001. Effects of topical anandamide-transport inhibitors, AM404 and olvanil, on intraocular pressure in normotensive rabbits. Pharm. Res. 18, 494-499.

Lee, D., Kim, K.Y., Noh, Y.H., Chai, S., Lindsey, J.D., Ellisman, M.H., Weinreb, R.N., Ju, W.K., 2012. Brimonidine blocks glutamate excitotoxicity-induced oxidative stress and preserves mitochondrial transcription factor a in ischemic retinal injury. PLoS One 7 (10), e47098.

Lee, D., Shim, M.S., Kim, K.Y., Noh, Y.H., Kim, H., Kim, S.Y., Weinreb, R.N., Ju, W.K., 2014. Coenzyme Q10 inhibits glutamate excitotoxicity and oxidative stress-mediated mitochondrial alteration in a mouse model of glaucoma. Invest. Ophthalmol. Vis. Sci. 55 (2), 993-1005.

Leske, M.C., Heiyl, A., Hussein, M., Bengtsson, B., Hyman, L., Komaroff, E., 2003. Factors for glaucoma progression and the effect of treatment: the early manifest glaucoma trial. Arch. Ophthalmol. 121, 48-56.

Leung, D.Y., Tham, C.C., Li, F.C., Kwong, Y.Y., Chi, S.C., Lam, D.S., 2009. Silent cerebral in farct and visual field progression in newly diagnosed normal-tension glaucoma. Ophthalmology 116, 1250-1256.

Levine, B., Klionsky, D.J., 2004. Development by self-digestion: molecular mechanisms and biological functions of autophagy. Dev. Cell 6, 463-477.

Levkovitch-Verbin, H., Martin, K.R., Quigley, H.A., Baumrind, L.A., Pease, M.E., Valenta, D. 2002. Measurement of amino acid levels in the vitreous humor of rats after chronic intraocular pressure elevation or optic nerve transection. J. Glaucoma 11 (5), 396-405.

Levkovitch-Verbin, H., Harizman, N., Dardik, R., Nisgav, Y., Vander, S., Melamed, S., 2007. Regulation of cell death and survival pathways in experimental glaucoma. Exp. Eye Res. 85, 250-258.

Lin, T.Y., Lu, C.W., Wu, C.C., Huang, S.K., Wang, S.J., 2015. Palmitoylethanolamide inhibits glutamate release in rat cerebrocortical nerve terminals. Int. J. Mol. Sci. 16 (3), $5555-5571$.

Lipton, S.A., 2003. Possible role for memantine in protecting retinal ganglion cells from glaucomatous damage. Surv. Ophthalmol. 48 (1), S38-S46.

Lipton, S.A., 2004. Failures and successes of NMDA receptor antagonists: molecular basis for the use of open-channel blockers like memantine in the treatment of acute and chronic neurologic insults. NeuroRx 1 (1), 101-110.

Lipton, S.A., Rosenberg, P.A., 1994. Excitatory amino acids as a final common pathway for neurologic disorders. N. Engl. J. Med 330 (9), 613-622.

Louzada-Júnior, P., Dias, J.J., Santos, W.F., Lachat, J.J., Bradford, H.F., Coutinho-Netto, J., 1992. Glutamate release in experimental ischaemia of the retina: an approach using microdialysis. J. Neurochem. 59 (1), 358-363.

Luo, X., Lambrou, G.N., Sahel, J.A., Hicks, D., 2001. Hypoglycemia induces general neuronal death, whereas hypoxia and glutamate transport blockade lead to selective retinal ganglion cell death in vitro. Invest. Ophthalmol. Vis. Sci. 42 (11), 2695-2705

Manabe, S., Lipton, S.A., 2003. Divergent NMDA signals leading to proapoptotic and antiapoptotic pathways in the rat retina. Invest. Ophthalmol. Vis. Sci. 44, 385-392.

Marsicano, G., Goodenough, S., Monory, K., Hermann, H., Eder, M., Cannich, A., Azad, S.C., Cascio, M.G., Gutiérrez, S.O., van der Stelt, M., López-Rodriguez, M.L., Casanova, E., Schütz, G., Zieglgänsberger, W., Di Marzo, V., Behl, C., Lutz, B., 2003. CB1 cannabinoid receptors and on-demand defense against excitotoxicity. Science 302, 84-88.

Martin, K.R., Levkovitch-Verbin, H., Valenta, D., Baumrind, L., Pease, M.E., Quigley, H.A. 2002. Retinal glutamate transporter changes in experimental glaucoma and after optic nerve transection in the rat. Invest. Ophthalmol. Vis. Sci. 43 (7), 2236-2243.

Martucci, A., Cesareo, M., Napoli, D., Sorge, R.P., Ricci, F., Mancino, R., Nucci, C., 2014. Evaluation of pupillary response to light in patients with glaucoma: a study using computerized pupillometry. Int. Ophthalmol. 34 (6), 1241-1247.

Mashima, Y., Kimura, I., Yamamoto, Y., Ohde, H., Ohtake, Y., Tanino, T., Tomita, G., Oguchi, Y., 2003. Optic disc excavation in the atrophic stage of Leber's hereditary optic neuropathy: comparison with normal tension glaucoma. Graefes Arch. Clin. Exp. Ophthalmol. 241 (2), 75-80.

Mastropasqua, R., Agnifili, L., Mattei, P.A., Caulo, M., Fasanella, V., Navarra, R., Mastropasqua, L., Marchini, G., 2015. Advanced Morphological and Functional Magnetic Resonance Techniques in Glaucoma. Biomed. Res. Int. 2015, 160454

Momjian-Mayor, I., Baron, J.C., 2005. The pathophysiology of watershed infarction in internal carotid artery disease: review of cerebral perfusion studies. Stroke 36 (3) 567-577.

Nakatogawa, H., Suzuki, K., Kamada, Y., Ohsumi, Y., 2009. Dynamics and diversity in autophagy mechanisms: lessons from yeast. Nat. Rev. Mol. Cell Biol. 10, 458-467.
Nakazawa, T., Tamai, M., Mori, N., 2002. Brain-derived neurotrophic factor prevents axotomized retinal ganglion cell death through MAPK and PI3K signaling pathways. Invest. Ophthalmol. Vis. Sci. 43, 3319-3326.

Nakazawa, T., Shimura, M., Tomita, H., Akiyama, H., Yoshioka, Y., Kudou, H., Tamai, M., 2003. Intrinsic activation of PI3K/Akt signaling pathway and its neuroprotective effect against retinal injury. Curr. Eye Res. 26, 55-63.

Nakazawa, T., Shimura, M., Endo, S., Takahashi, H., Mori, N., Tamai, M., 2005. N-Methyl-DAspartic acid suppresses Akt activity through protein phosphatase in retinal ganglion cells. Mol. Vis. 11, 1173-1182.

Naskar, R., Vorwerk, C.K., Dreyer, E.B., 2000. Concurrent downregulation of a glutamate transporter and receptor in glaucoma. Invest. Ophthalmol. Vis. Sci. 41 (7), 1940-1944.

Newman, N.J., 1993. Leber's hereditary optic neuropathy. New genetic considerations. Arch. Neurol. 50, 540-548.

Nowacka, B., Lubinski, W., Honczarenko, K., Potemkowski, A., Safranow, K., 2014. Ophthalmological features of Parkinson disease. Med Sci. Monit. 20, 2243-2249.

Nucci, C., Morrone, L., Rombolà, L., Nisticò, R., Piccirilli, S., Cerulli, L., 2003. Multifaceted roles of nitric oxide in the lateral geniculate nucleus: from visual signal transduction to neuronal apoptosis. Toxicol. Lett. 139 (2-3), 163-173.

Nucci, C., Cedrone, C., Culasso, F., Ricci, F., Cesareo, M., Corsi, A., Cerulli, L., 2005a. Incidence of visual loss in the Ponza Eye Study. Italy Eye 19 (2), 175-182.

Nucci, C., Tartaglione, R., Rombolà, L., Morrone, L.A., Fazzi, E., Bagetta, G., 2005b. Neurochemical evidence to implicate elevated glutamate in the mechanisms of high intraocular pressure (IOP)-induced retinal ganglion cell death in rat. Neurotoxicology 26 (5), 935-941.

Nucci, C., Tartaglione, R., Cerulli, A., Mancino, R., Spanò, A., Cavaliere, F., Rombolà, L. Bagetta, G., Corasaniti, M.T., Morrone, L.A., 2007a. Retinal damage caused by high intraocular pressure-induced transient ischemia is prevented by coenzyme Q10 in rat. Int. Rev. Neurobiol. 82, 397-406.

Nucci, C. Gasperi, V., Tartaglione, R., Cerulli, A., Terrinoni, A., Bari, M., De Simone, C., Agrò, A.F., Morrone, L.A., Corasaniti, M.T., Bagetta, G., Maccarrone, M., 2007b. Involvement of the endocannabinoid system in retinal damage after high intraocular pressureinduced ischemia in rats. Invest. Ophthalmol. Vis. Sci. 48 (7), 2997-3004.

Nucci, C., Bari, M., Spanò, A., Corasaniti, M., Bagetta, G., Maccarrone, M., Morrone, L.A., 2008. Potential roles of (endo)cannabinoids in the treatment of glaucoma: from intraocular pressure control to neuroprotection. Prog. Brain Res. 173, 451-464.

Nucci, C., Martucci, A., Martorana, A., Sancesario, G.M., Cerulli, L., 2011. Glaucoma progression associated with altered cerebral spinal fluid levels of amyloid beta and tau proteins. Clin. Exp. Ophthalmol. 39 (3), 279-281.

Nucci, C., Mancino, R., Martucci, A., Bolacchi, F., Manenti, G., Cedrone, C., Culasso, F., Floris, R., Cerulli, L., Garaci, F.G., 2012. 3-T Diffusion tensor imaging of the optic nerve in subjects with glaucoma: correlation with GDx-VCC, HRT-III and Stratus optical coherence tomography findings. Br. J. Ophthalmol. 96 (7), 976-980.

Nucci, C., Martucci, A., Cesareo, M., Mancino, R., Russo, R., Bagetta, G., Cerulli, L., Garaci, F. G., 2013a. Brain involvement in glaucoma: advanced neuroimaging for understanding and monitoring a new target for therapy. Curr. Opin. Pharm. 13 (1), 128-133.

Nucci, C., Martucci, A., Mancino, R., Cerulli, L., 2013b. Glaucoma progression associated with Leber's hereditary optic neuropathy. Int. Ophthalmol. 33 (1), 75-77.

Nucci, C., Martucci, A., Cesareo, M., Garaci, F., Morrone, L.A., Russo, R., Corasaniti, M.T., Bagetta, G., Mancino, R., 2015. Links among glaucoma, neurodegenerative, and vascular diseases of the central nervous system. Prog. Brain Res. 221, 49-65.

Njie, Y.F., Kumar, A., Qiao, Z., Zhong, L., Song, Z.H., 2006. Noladin ether acts on trabecular meshwork cannabinoid (CB1) receptors to enhance aqueous humor outflow facility. Invest. Ophthalmol. Vis. Sci. 47, 1999-2005.

Osborne, N.N., Lascaratos, G., Bron, A.J., Chidlow, G., Wood, J., 2006. A hypothesis to suggest that light is a risk factor in glaucoma and the mitochondrial optic neuropathies. Br. J. Ophthalmol. 90, 237-241.

Pantoni, L., Garcia, J.H., 1997. Pathogenesis of leukoaraiosis: a review. Stroke 28, 652-659.

Papucci, L., Schiavone, N., Witort, E., Donnini, M., Lapucci, A., Tempestini, A., Formigli, L., Zecchi-Orlandini, S., Orlandini, G., Carella, G., Brancato, R., Capaccioli, S., 2003. Coenzyme q10 prevents apoptosis by inhibiting mitochondrial depolarization independently of its free radical scavenging property. J. Biol. Chem. 278 (30), 28220-28228.

Park, H.Y., Kim, J.H., Park, C.K., 2012. Activation of autophagy induces retinal ganglion cell death in a chronic hypertensive glaucoma model. Cell Death Dis. 3, e290.

Pate, D.W., Jarvinen, K., Urtti, A., Jarho, P., Jarvinen, T., 1995. Ophthalmic arachidonylethanolamide decreases intraocular pressure in normotensive rabbits. Curr. Eye Res. 14, 791-797.

Patel, M., Day, B.J., Crapo, J.D., Fridovich, I., McNamara, J.O., 1996. Requirement for superoxide in excitotoxic cell death. Neuron 16 (2), 345-355.

Pawlak, J., Brito, V., Küppers, E., Beyer, C., 2005. Regulation of glutamate transporter GLAST and GLT-1 expression in astrocytes by estrogen. Brain Res. Mol. Brain Res. 138 (1), 1-7.

Pelletier, A.A., Théorět, M.Ė., Boutin, T., Kergoat, M.J., Massoud, F., Latour, J., Chayer, C., Kergoat, H., 2014. Prevalence of glaucoma in hospitalized older adults with Alzheimer's disease. Can. J. Neurol. Sci. 41 (2), 206-209.

Piras, A., Gianetto, D., Conte, D., Bosone, A., Vercelli, A., 2011. Activation of autophagy in a rat model of retinal ischemia following high intraocular pressure. PloS One 6, e22514.

Pryce, G., Ahmed, Z., Hankey, D.J., Jackson, S.J., Croxford, J.L., Pocock, J.M., Ledent, C., Petzold, A., Thompson, A.J., Giovannoni, G., Cuzner, M.L., Baker, D., 2003. Cannabinoids inhibit neurodegeneration in models of multiple sclerosis. Brain 126 (10) 2191-2202.

Qi, Y., Chen, L., Zhang, L., Liu, W.B., Chen, X.Y., Yang, X.G., 2013. Crocin prevents retinal ischaemia/reperfusion injury-induced apoptosis in retinal ganglion cells through the PI3K/AKT signalling pathway. Exp. Eye Res. 107, 44-51.

Regine, F., Scuderi, G.L., Cesareo, M., Ricci, F., Cedrone, C., Nucci, C., 2006. Validity and limitations of the Nidek NT-4000 non-contact tonometer: a clinical study. Ophthalmic Physiol. Opt. 26 (1), 33-39.

Rodriguez-Muela, N., Germain, F., Marino, G., Fitze, P.S., Boya, P., 2012. Autophagy promotes survival of retinal ganglion cells after optic nerve axotomy in mice. Cell Death Differ. 19, 162-169.

Rodriguez-Muela, N., Boya, P., 2012. Axonal damage, autophagy and neuronal survival, 
Autophagy 8, 286-288.

Russo, R., Cavaliere, F., Berliocchi, L., Nucci, C., Gliozzi, M., Mazzei, C., Tassorelli, C., Corasaniti, M.T., Rotiroti, D., Bagetta, G., Morrone, L.A., 2008a. Modulation of pro-survival and death-associated pathways under retinal ischemia/reperfusion: effects of NMDA receptor blockade. J. Neurochem. 107, 1347-1357.

Russo, R., Cavaliere, F., Rombolà, L., Gliozzi, M., Cerulli, A., Nucci, C., Fazzi, E., Bagetta, G., Corasaniti, M.T., Morrone, L.A., 2008b. Rational basis for the development of coenzyme Q10 as a neurotherapeutic agent for retinal protection. Prog. Brain Res. 173, $575-582$.

Russo, R., Rotiroti, D., Tassorelli, C., Nucci, C., Bagetta, G., Bucci, M.G., Corasaniti, M.T., Morrone, L.A., 2009. Identification of novel pharmacological targets to minimize excitotoxic retinal damage. Int. Rev. Neurobiol. 85, 407-423.

Russo, R., Berliocchi, L., Adornetto, A., Varano, G.P., Cavaliere, F., Nucci, C., Rotiroti, D., Morrone, L.A., Bagetta, G., Corasaniti, M.T., 2011. Calpain-mediated cleavage of Beclin-1 and autophagy deregulation following retinal ischemic injury in vivo. Cell Death Dis. 2, e144.

Russo, R., Berliocchi, L., Adornetto, A., Amantea, D., Nucci, C., Tassorelli, C., Morrone, L.A., Bagetta, G., Corasaniti, M.T., 2013a. In search of new targets for retinal neuroprotection: is there a role for autophagy? Curr. Opin. Pharmacol. 13 (1), 72-77.

Russo, R., Cavaliere, F., Varano, G.P., Milanese, M., Adornetto, A., Nucci, C., Bonanno, G., Morrone, L.A., Corasaniti, M.T., Bagetta, G., 2013b. Impairment of neuronal glutamate uptake and modulation of the glutamate transporter GLT-1 induced by retinal ischemia. PLoS One 8, e69250.

Russo, R., Adornetto, A., Cavaliere, F., Varano, G.P., Rusciano, D., Morrone, L.A., Corasaniti, M.T., Bagetta, G., Nucci, C., 2015a. Intravitreal injection of forskolin, homotaurine, and $\mathrm{L}$-carnosine affords neuroprotection to retinal ganglion cells following retinal ischemic injury. Mol. Vis. 21, 718-729.

Russo, R., Nucci, C., Corasaniti, M.T., Bagetta, G., Morrone, L.A., 2015b. Autophagy dysregulation and the fate of retinal ganglion cells in glaucomatous optic neuropathy. Prog. Brain Res. 220, 87-105.

Silverberg, G., Mayo, M., Saul, T., Fellmann, J., McGuire, D., 2006. Elevated cerebrospinal fluid pressure in patients with Alzheimer's disease. Cerebrospinal Fluid Res. 31 (3), 7.

Sakamoto, K., Endo, K., Suzuki, T., Fujimura, K., Kurauchi, Y., Mori, A., Nakahara, T., Ishii, K., 2015. P2 $\times 7$ receptor antagonists protect against $\mathrm{N}$-methyl-D-aspartic acid-induced neuronal injury in the rat retina. Eur. J. Pharmacol. 5 (756), 52-58.

Salt, T.E., Cordeiro, M.F., 2006. Glutamate excitotoxicity in glaucoma: throwing the baby out with the bathwater? Eye 20 (6), 731-732 730-1; author reply.

Santos-Carvalho, A., Elvas, F., Alvaro, A.R., Ambrósio, A.F., Cavadas, C., 2013. Neuropeptide Y receptors activation protects rat retinal neural cells against necrotic and apoptotic cell death induced by glutamate. Cell Death Dis. 16 (4), e636.

Sena, D.F., Lindsley, K., 2013. Neuroprotection for treatment of glaucoma in adults. Cochrane Database Syst. Rev. 2, CD006539. http://dx.doi.org/10.1002/14651858. CD006539.pub3.

Sinor, A.D., Irvin, S.M., Greenberg, D.A., 2000. Endocannbinoids protect cerebral cortical neurons from in vitro ischemia in rats. Neurosci. Lett. 278, 157-160.

Slusar, J.E., Cairns, E.A., Szczesniak, A.M., Bradshaw, H.B., Di Polo, A., Kelly, M.E., 2013. The fatty acid amide hydrolase inhibitor, URB597, promotes retinal ganglion cell neuroprotection in a rat model of optic nerve axotomy. Neuropharmacology 72, 116-125.

Su, W., Li, Z., Jia, Y., Zhuo, Y., 2014. Rapamycin is neuroprotective in a rat chronic hypertensive glaucoma model. PLoS One 9, e99719.

Sucher, N.J., Lipton, S.A., Dreyer, E.B., 1997. Molecular basis of glutamate toxicity in retinal ganglion cells. Vis. Res. 37, 3483-3493.

Tamura, H., Kawakami, H., Kanamoto, T., Kato, T., Yokoyama, T., Sasaki, K., Izumi, Y., Matsumoto, M., Mishima, H.K., 2006. High frequency of open angle glaucoma in Japanese patients with Alzheimer's disease. J. Neurol. Sci. 246 (1-2), 79-83.

Tezel, G., 2006. Oxidative stress in glaucomatous neurodegeneration: mechanisms and consequences. Prog. Retin Eye Res. 25 (5), 490-513.

Thouin, A., Griffiths, P.G., Hudson, G., Chinnery, P.F., Yu-Wai-Man, P., 2013. Raised intraocular pressure as a potential risk factor for visual loss in Leber Hereditary Optic Neuropathy. PLoS One 8 (5), e63446.

Tomida, I., Pertwee, R.G., Azuara-Blanco, A., 2004. Cannabinoids and glaucoma. Br. J.
Ophthalmol. 88 (5), 708-713.

Tsironi, E.E., Dastiridou, A., Katsanos, A., Dardiotis, E., Veliki, S., Patramani, G., Zacharaki, F., Ralli, S., Hadjigeorgiou, G.M., 2012. Perimetric and retinal nerve fiber layer findings in patients with Parkinson's disease. BMC Ophthalmol. 12, 54.

Tsuda, Y., Nakahara, T., Ueda, K., Mori, A., Sakamoto, K., Ishii, K., 2012. Effect of nafamosta on $\mathrm{N}$-methyl-D-aspartate-induced retinal neuronal and capillary degeneration in rats. Biol. Pharm. Bull. 35 (12), 2209-2213.

Valiente-Soriano, F.J., Nadal-Nicolás, F.M., Salinas-Navarro, M., Jiménez-López, M., BernalGarro, J.M., Villegas-Pérez, M.P., Agudo-Barriuso, M., Vidal-Sanz, M., 2015. BDNF rescues RGCs but not intrinsically photosensitive RGCs in ocular hypertensive albino rat retinas. Invest. Ophthalmol. Vis. Sci. 56 (3), 1924-1936.

Vidal, L., Díaz, F., Villena, A., Moreno, M., Campos, J.G., Pérez de Vargas, I., 2010. Reaction of Müller cells in an experimental rat model of increased intraocular pressure following timolol, latanoprost and brimonidine. Brain Res. Bull. 82 (1-2), 18-24.

Vidal-Sanz, M., Nadal-Nicolás, F.M., Valiente-Soriano, F.J., Agudo-Barriuso, M., VillegasPérez, M.P., 2015. Identifying specific RGC types may shed light on their idiosyncratic responses to neuroprotection. Neural Regen. Res. 10 (8), 1228-1230.

Villena, A., Diaz, F., Vidal, L., Moreno, M., Garcia-Campos, J., Perez De Vargas, I., 2009. Study of the effects of ocular hypotensive drugs on number of neurons in the retina ganglion layer in a rat experimental glaucoma. Eur. J. Ophthalmol. 19 (6), 963-970.

Wamsley, S., Gabelt, B.T., Dahl, D.B., Case, G.L., Sherwood, R.W., May, C.A., Hernandez, M. R., Kaufman, P.L., 2005. Vitreous glutamate concentration and axon loss in monkeys with experimental glaucoma. Arch. Ophthalmol. 123, 64-70.

Weber, A.J., Chen, H., Hubbard, W.C., Kaufman, P.L., 2000. Experimental glaucoma and cell size, density, and number in the primate lateral geniculate nucleus. Invest. Ophthalmol. Vis. Sci. 41, 1370-1379.

Wei, T., Kang, Q., Ma, B., Gao, S., Li, X., Liu, Y., 2015. Activation of autophagy and paraptosis in retinal ganglion cells after retinal ischemia and reperfusion injury in rats. Exp. Ther. Med. 9, 476-482.

Weishaupt, J.H., Rohde, G., Polking, E., Siren, A.L., Ehrenreich, H., Bahr, M., 2004. Effect of erythropoietin axotomy-induced apoptosis in rat retinal ganglion cells. Invest. Ophthalmol. Vis. Sci. 45, 1514-1522.

Wheeler, L., WoldeMussie, E., Lai, R., 2003. Role of alpha-2 agonists in neuroprotection. Surv. Ophthalmol. 48 Suppl 1, S47-S51.

WoldeMussie, E., Yoles, E., Schwartz, M., Ruiz, G., Wheeler, L.A., 2002. Neuroprotective effect of memantine in different retinal injury models in rats. J. Glaucoma 11, 474-480.

Wostyn, P., Audenaert, K., De Deyn, P.P., 2008. An abnormal high trans-lamina cribrosa pressure difference: a missing link between Alzheimer's disease and glaucoma? Clin. Neurol. Neurosurg. 110 (7), 753-754.

Wostyn, P., De Groot, V., Van Dam, D., Audenaert, K., De Deyn, P.P., 2013. Senescent changes in cerebrospinal fluid circulatory physiology and their role in the pathogenesis of normal-tension glaucoma. Am. J. Ophthalmol. 156 (1), 5-14, e2.

Yanagisawa, M., Aida, T., Takeda, T., Namekata, K., Harada, T., Shinagawa, R., Tanaka, K., 2015. Arundic acid attenuates retinal ganglion cell death by increasing glutamate/ aspartate transporter expression in a model of normal tension glaucoma. Cell Death Dis. 19 (6), e1693.

Yazulla, S., 2008. Endocannabinoids in the retina: from marijuana to neuroprotection Prog. Retin Eye Res. 27 (5), 501-526.

Yenice, O., Onal, S., Midi, I., Ozcan, E., Temel, A., I-Gunal, D., 2008. Visual field analysis in patients with Parkinson's disease. Park. Relat. Disord. 14, 193-198.

Yücel, Y.H., Zhang, Q., Gupta, N., Kaufman, P.L., Weinreb, R.N., 2000. Loss of neurons in magnocellular and parvocellular layers of the lateral geniculate nucleus in glaucoma. Arch. Ophthalmol. 118, 378-384.

Yücel, Y.H., Zhang, Q., Weinreb, R.N., Kaufman, P.L., Gupta, N., 2003. Effects of retinal ganglion cell loss on magno-, parvo-, koniocellular pathways in the lateral geniculate nucleus and visual cortex in glaucoma. Prog. Retin Eye Res. 22, 465-481.

Zhong, L., Bradley, J., Schubert, W., Ahmed, E., Adamis, A.P., Shima, D.T., Robinson, G.S., $\mathrm{Ng}$, Y.S., 2007. Erythropoietin promotes survival of retinal ganglion cells in DBA/2J glaucoma mice. Invest. Ophthalmol. Vis. Sci. 48 (3), 1212-1218. 